\title{
Sistem Kontrol Rumah Pintar Menggunakan Kamera Berbasis IoT
}

\author{
Monita $^{1}$, Hendri ${ }^{2}$ \\ ${ }^{12}$ Universitas Negeri Padang \\ JI. Prof. Hamka Air Tawar, Padang, Indonesia \\ monitaputri33@gmail.com ${ }^{1}$
}

\begin{abstract}
The high crime rate has been one of the consequences of the economic crisis in Indonesia. More crimes have been committed, especially in terms of theft and robbery. The research aims to to design a smart home control system using a Logitech camera of C270 HD web cam type, a raspberry pi 3 model B as a control center, a PIR sensor as a tool to send notifications to clients when it detects motion, and a smartphone as mp4 data receivers if there is data processed via the telegram application. The test is carried out by applying the quantitative research method using the data in the form of numbers to analyze the information to make it looks more detailed and clear. The test results are presented in tabular forms in order to make them easy to understand. Once the test process has been completed, the designed camera is mounted on the prototype and on the porch of the house therefore the client can receive video if there is activation around the porch of the house. Moreover, the clients can also detect remotely via the Telegram app on smartphones. The results of the test shows that the overall function is quite good and takes 3-18 seconds of video duration.
\end{abstract}

Keywords - Smart home, IoT, Raspberry pi 3 model B, Sensor PIR, logitech C270 HD Webcam.

\begin{abstract}
Abstrak - Tingginya angka kriminalitas di Indonesia merupakan salah satu akibat dari krisis ekonomi. Tentunya tindakan kejahatan semakin banyak dilakukan, terutama dalam hal pencurian dan perampokan. Pemaparan dari hasil tugas akhir yang bertujuan untuk merancang sistem kontrol rumah pintar menggunakan kamera dengan type kamera logitech C270 HD web cam serta raspberry pi 3 model B sebagai pusat pengontrolan, sensor PIR berfungsi untuk mengirimkan notifikasi terhadap klien ketika mendeteksi adanya gerakan, serta smartphone sebagai penerima data mp4 jika ada data diproses melalui aplikasi telegram. Pada tugas akhir ini, penulis menggunakan metode penelitian kuantitatif. Dimana pengujian dilakukan menggunakan data berupa angka untuk menganalisis keterangan yang ingin diketahui sehingga terlihat lebih detail dan jelas. Untuk memudahkan pembacaan, penulis menggunakan tabel-tabel sebagai penjabaran hasil pengujian. Setelah pengujian, kamera dipasang di prototype dan di teras rumah sehingga klien bisa menerima video jika ada aktifias di sekitar teras rumah. Klien bisa mendeteksi dari jarak jauh melalui aplikasi Telegram di smartphone. Data yang diambil menunjukkan bahwa fungsi keseluruhan cukup baik dan membutuhkan waktu 3-18 detik durasi video.
\end{abstract}

Kata kunci-Rumah Pintar, IoT, Raspberry pi 3 model B, Sensor PIR, logitech C270 HD Webcam.

\section{Pendahuluan}

Meningkatnya kejahatan akhir-akhir ini merupakan salah satu akibat dari krisis ekonomi. Sebab, di tengah wabah Covid-19, aktivitas ekonomi masyarakat dibatasi. Namun, tak jarang di antara pelaku kriminal ini melakukan aksinya karena ingin memenuhi kebutuhan hidup. Tentunya tindakan kejahatan semakin banyak dilakukan, terutama dalam hal pencurian dan perampokan. Kejadian tersebut biasanya terjadi ketika penghuni beraktifitas jauh dari rumah dengan tingkat kesibukan yang tinggi. Sehingga penghuni rumah menjadi khawatir ketika hendak meninggalkan rumah. Maka, diperlukan sistem keamanan yang dapat menjaga harta maupun privasi yang ada didalam rumah.

Smart home adalah aplikasi gabungan antara teknologi dan pelayanan yang dikhususkan pada lingkungan rumah dengan fungsi tertentu yang bertujuan meningkatkan keamanan, efisiensi dan kenyamanan penghuninya [1]. Smart home dilengkapi dengan sistem otomatisasi untuk menyediakan fungsi kontrol dan pemantauan kondisi rumah. Smart home menggabungkan kebutuhan akan lingkungan yang aman dan nyaman, mendukung terciptanya lingkungan yang lebih hijau [2].

Perkembangan teknologi semakin pesat dari waktu ke waktu, salah satunya Internet of Things. Internet of Things merupakan perkembangan keilmuan yang sangat menjanjikan untuk mengoptimalkan kehidupan berdasarkan sensor cerdas dan peralatan pintar yang bekerja sama melalui jaringan internet [3]. Internet of Things bekerja ketika suatu benda harus memiliki sebuah alamat Internet Protocol (IP) [4]. Untuk mengontrol sebuah objek, diperlukan sebuah kontroler yakni raspberry. Raspberry (juga dikenal sebagai RasPi) adalah sebuah SBC (Single Board Computer) single board 
computer, salah satunya adalah Raspberry Pi. Saat ini Raspberry Pi banyak digunakan sebagai pengganti fungsi CPU, dan diterapkan pula pada perkembangan robot vision dan computer vision [5]. Raspberry pi 3 dilengkapi konektifitas wifi, bluetooth, dan ethernet yang sudah tertanam secara built-in untuk mengambil video aktifitas disekitar rumah.

Penerapan sistem keamanan rumah juga perlu suatu input yakni PIR (Passive Infrared Receiver) merupakan sebuah sensor berbasiskan infrared. Akan tetapi, tidak seperti sensor infrared kebanyakan yang terdiri dari IR LED dan fototransistor. Sensor PIR sangat populer digunakan untuk sistem keamanan dan sistem pengolahan energi karena sensor ini bersifat sederhana, relatif murah, responsivitasnya tinggi, dan memiliki rentang dinamik yang lebar [6]. Benda yang bisa dideteksi oleh sensor ini biasanya adalah tubuh manusia, sehingga PIR akan deteksi orang masuk atau tidak yang nantinya akan dikontrol jarak jauh oleh pengguna melalui smartphone. Smartphone atau ponsel pintar telah menjadi bagian penting dalam kehidupan manusia dimana tidak hanya digunakan sebagai alat komunikasi saja tetapi juga bermanfaat dalam memenuhi kebutuhan manusia [7].

Untuk mendapatkan hasil maksimal, penulis juga menambahkan webcam sebagai kamera video digital yang sengaja didesain sebagai kamera dengan resolusi rendah. Webcam dapat digunakan untuk sistem keamanan agar memudahkan pengguna melihat situasi rumah [8]. Web camera biasanya dilengkapi dengan software, software ini mengambil gambar-gambar dari kamera digital secara terus menerus ataupun dalam interval waktu tertentu dan menyiarkannya melalui koneksi internet. Nantinya sumber dari alat tersebut dipakai adaptor pabrikan. Adaptor Power Supply adalah adaptor yang dapat merubah tegangan listrik AC yang besar menjadi tegangan DC. Berbagai topologi sirkuit dan teknik kontrol telah dikembangkan yang bertujuan untuk mengurangi gangguan kualitas daya [9]. Untuk menjaga kestabilan raspberry, adaptor pabrikan aman digunakan.

Berdasarkan paparan diatas, penulis mengambil bidang tersebut dikarenakan webcam adalah suatu alat kontrol yang mudah digunakan dan dapat memudahkan pemilik rumah untuk mengontrol aktifitas rumah dari jarak jauh. Selain itu, penulis menambahkan sensor PIR karena sensor sangat cocok untuk deteksi objek yang nantinya sangat berguna dalam sistem kontrol jika ada orang asing masuk ke rumah.

Tujuan dari penelitian ini adalah untuk mengetahui prinsip webcam dan sensor PIR, jarak maksimal yang dideteksi sensor PIR, dan juga durasi respon sensor PIR dan webcam terhadap objek yang dideteksi.

\section{METODE}

\section{A. Diagram Blok}

Blok diagram adalah pendefinisian terhadap sistem yang akan dirancangkan yang bersifat menyeluruh, blok diagram dari Tugas Akhir ini dapat dilihat pada gambar 1 dibawah ini.

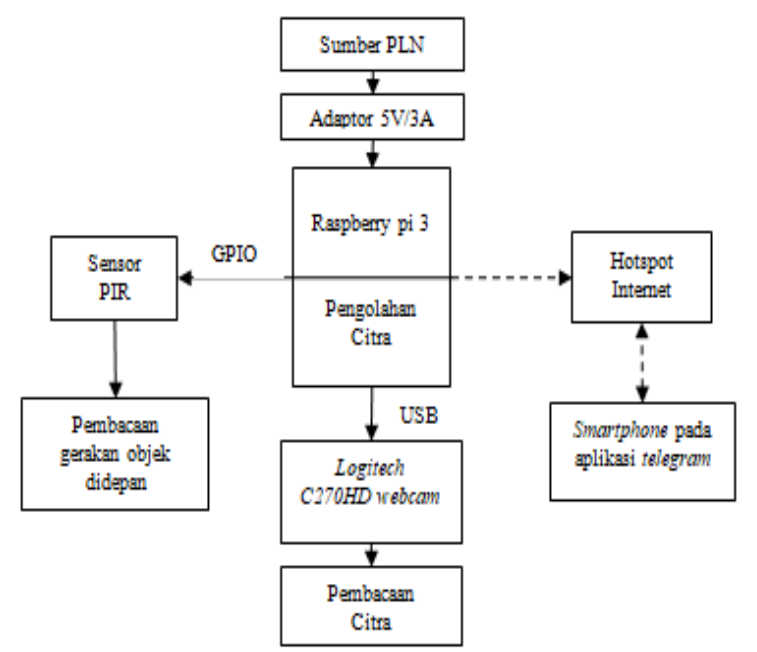

Gambar 1. Blok Diagram Sistem

Berdasarkan blok diagram keseluruhan sistem diatas fungsi dari masing-masing blok dapat dijelaskan sebagai berikut:

1. Raspberry pi 3

Raspberry pi 3 berfungsi untuk menerima data dari sensor PIR serta memperoses data apakah ada gerakan atau tidak teras rumah, lalu logitech HD270 webcam menangkap citra dari gerakan tersebut. Karena raspberry pi 3 dilengkapi konektifitas wifi, bluetooth, dan ethernet yang sudah tertanam secara built-in untuk mengambil video aktifitas disekitar rumah. Jika perintah cocok maka video akan terkirim melalui telegram di smartphone.

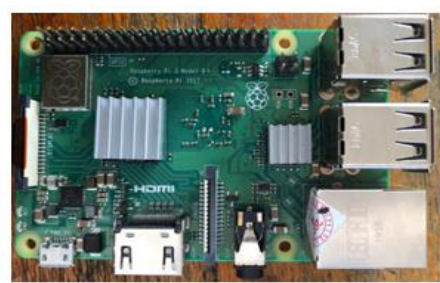

Gambar 2. Raspberry pi 3

\section{Sensor PIR}

Sensor PIR nantinya akan dipasang didekat webcam. Ketika seseorang berjalan melewati sensor, sensor akan menangkap pancaran sinar inframerah pasif yang dipancarkan oleh tubuh manusia yang memiliki suhu yang berbeda dari lingkungan. Lalu, diproses oleh raspberry untuk dikirim ke smartphone. 


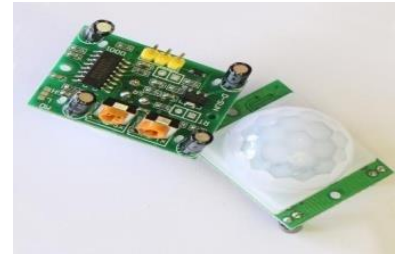

Gambar 3. Sensor PIR

3. Adaptor Power Supply

Adaptor yang digunakan adaptor pabrikan yang berawal dari sumber PLN yang tegangan 220V AC menjadi tegangan 5VDC, 3 VDC.

4. Smartphone

Smartphone akan memantau serta akan mengontrol aktifitas di depan teras rumah melalui sebuah aplikasi telegram. Aplikasi Telegram dapat digunakan pada perangkat ponsel smartphone, tablet, atau perangkat komputer.

5. Hotspot

Hotspot internet / Mini wi-fi digunakan sebagai penyedia jaringan untuk mengakses internet atau membuka halaman web.

6. Logitech $270 H D$ webcam

Kamera digunakan sebagai perekam aktifitas yang terjadi disekitar rumah dalam bentuk video dan juga sebagai perantara yang menghubungkan smartphone dengan jaringan wi-fi.

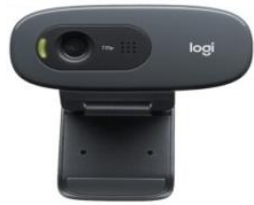

Gambar 4. Logitech C270HD webcam

\section{B. Flowchart}

Diagram alir atau flowchart berfungsi sebagai acuan dalam membuat listing program. Pada Flowchart berisi penentuan instruksi-instruksi dari program yang akan dibuat. Rancangan flowchart sistem dari tugas akhir ini dapat dilihat pada gambar 5 berikut.

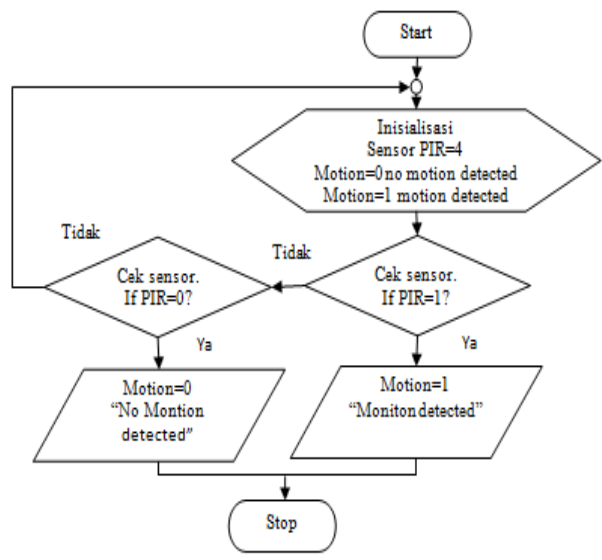

Gambar 5. Flowchart notifikasi sensor PIR
Rancangan flowchart dari sistem kamera dan raspberry dapat dilihat pada gambar 6 berikut.

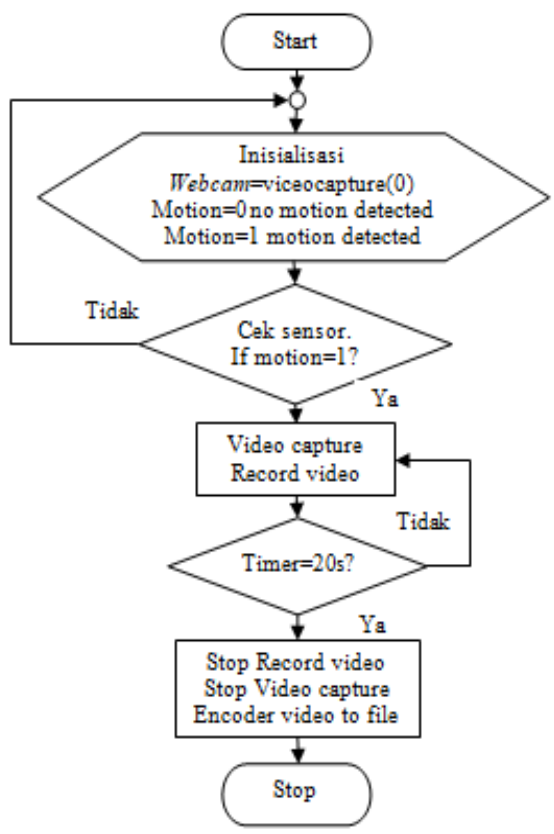
Gambar 6. Flowchart notifikasi logitech 270HD
webcam

Rancangan flowchart dari sistem telegram dapat dilihat pada gambar 7 berikut.

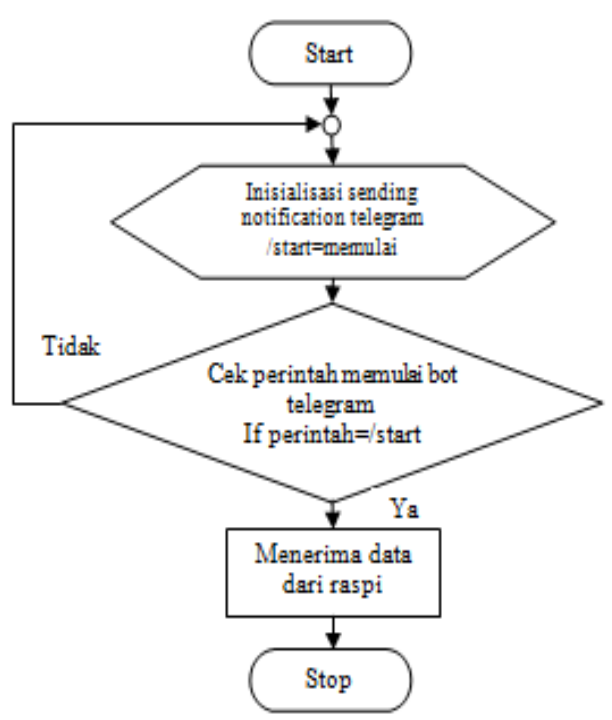

Gambar 7. Flowchart notifikasi telegram

C. Perancangan Hardware

Hardware juga merupakan bagian penting dari alat. Pada bagian ini akan diperlihatkan gambar 8 yang berupa desain dari alat yang akan dibuat. Alat mempunyai volume $70 \times 50 \times 30$ dalam centimeter, dan pada desain ditampilkan penempatan kamera dan sensor. 


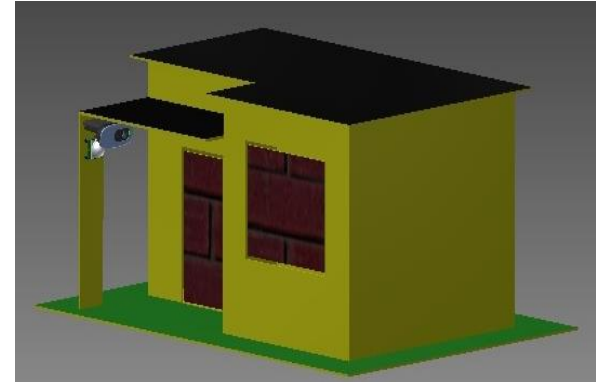

Gambar 8. Penempatan Webcam dan Sensor PIR

\section{HASILDANPEMBAHASAN}

Pada bagian hasil dan pembahasan, akan dilakukan beberapa pengujian dan analisa pada seluruh bagian input dan output alat. Tujuan pengujian dan analisa ini untuk mendapatkan data-data serta bukti hasil akhir dari kenyataan bahwa perangkat keras yang telah dibuat bisa bekerja dengan baik dan dapat digabungkan dengan perangkat lunak sesuai dengan yang direncanakan.

1. Pengujian Mekanik

Sebagai perbandingan hasil dari desain penempatan kamera dan sensor dengan hasil pengujian berikut adalah bentuk Hardware yang bisa dilihat pada gambar 9 berikut ini.

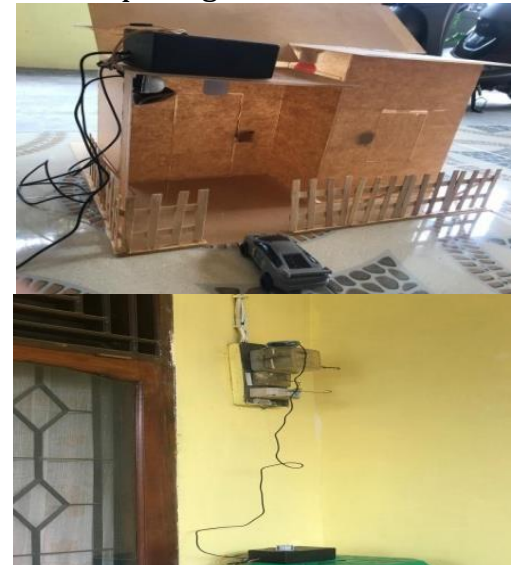

Gambar 9. Rancangan Penempatan Webcam di Prototype Rumah dan Rumah Nyata

Pada gambar 9 terlihat bahwa penempatan webcam di prototype rumah hampir mirip dengan perancangan dan posisi masing-masing komponen sesuai dengan desain gambar.

2. Pengujian Alat

Pengujian ini dilakukan untuk melihat berfungsi atau tidaknya rangkaian sistem mendeteksi aktifitas di rumah. Hasil pengujian ini memperlihatkan bahwa sistem bekerja dengan baik dengan indikator raspberry menyalanya lampu masing-masing alat seperti terlihat pada gambar 10 sebagai berikut.

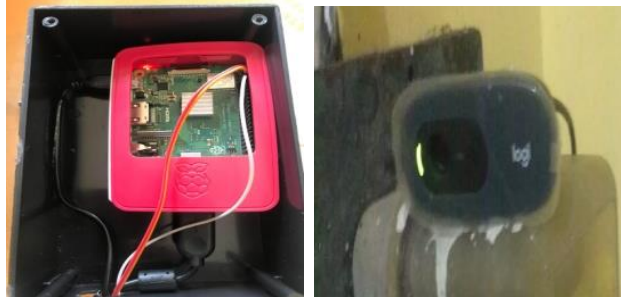

Gambar 10. Indikator Pada Raspberry pi dan webcam

3. Pengujian Software

Dimulai dari mendapatkan alamat ip menggunakan software fing, dan software VNC (Virtual network computing) untuk penginputan alamat ip. Agar sistem dapat berjalan maka dibuat program menggunakan software python IDE. Selanjutnya, membuka aplikasi telegram dengan memulai start lalu kita milih resolusi yang diinginkan, kemudian sensor PIR mendeteksi gerakan di depan rumah prototype dan nyata, lalu webcam aktif menangkap citra atau gambar maka raspberry akan memproses citra tersebut. Setelah itu, data tersebut terkirim ke aplikasi telegram "Security camera is activated". Selanjutnya, beberapa detik citra/gambar akan terkirim dalam bentuk video atau dalam bentuk file mp4. Jika video terkirim, maka raspberry akan mengirim kembali notifikasi "The motion sensor is triggered". Berikut gambar 11 bentuk notifikasi telegram.

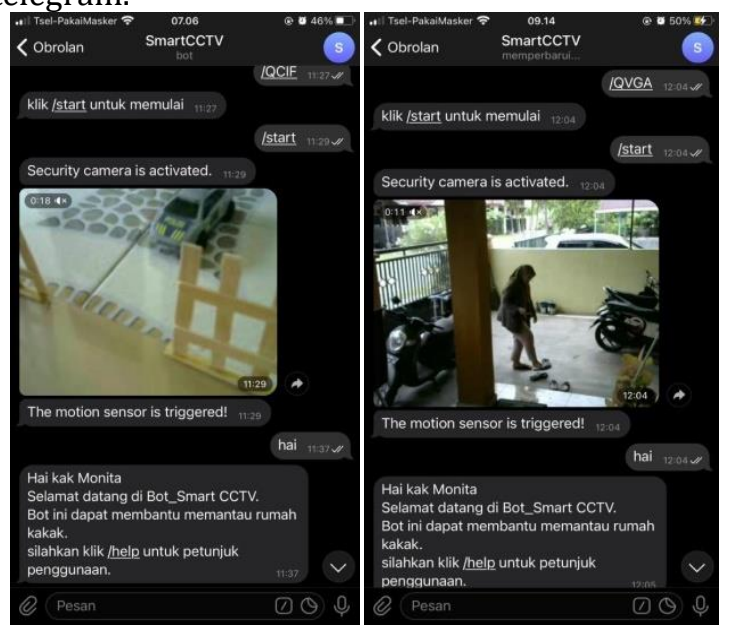

Gambar 11. Notifikasi Telegram pada Prototype dan Rumah nyata

4. Hasil Pengujian Jarak dan Sudut Sensor

Pengujian ini bertujuan menguji sensitifitas sensor terhadapat jarak. Pengujian dilakukan pada rumah mini dan juga real, tujuan pengujian tersebut untuk membandingkan ketepatan sensor menangkap objek. Hasil pengujian diperlihatkan pada tabel 1 dan 2 . 
Tabel 1. Pengujian Jarak Sensor tempat prototype rumah.

\begin{tabular}{|c|c|c|c|c|c|c|}
\hline \multirow{2}{*}{ Sudut } & \multicolumn{7}{|c|}{ Jarak } \\
\cline { 2 - 7 } & $10 \mathrm{~cm}$ & $20 \mathrm{~cm}$ & $40 \mathrm{~cm}$ & $60 \mathrm{~cm}$ & $80 \mathrm{~cm}$ & $100 \mathrm{~cm}$ \\
\hline $0^{\circ}$ & $\sqrt{ }$ & $\sqrt{ }$ & $\sqrt{ }$ & $\sqrt{ }$ & $\sqrt{ }$ & $\sqrt{ }$ \\
\hline $65^{\circ}$ & $\sqrt{ }$ & $\sqrt{ }$ & $\sqrt{ }$ & $\sqrt{ }$ & $\sqrt{ }$ & $\sqrt{ }$ \\
\hline $90^{\circ}$ & $\sqrt{ }$ & $\sqrt{ }$ & $\sqrt{ }$ & $\sqrt{ }$ & $\sqrt{ }$ & $\sqrt{ }$ \\
\hline $120^{\circ}$ & $\sqrt{ }$ & $\sqrt{ }$ & $\sqrt{ }$ & $\sqrt{ }$ & $\sqrt{ }$ & $\sqrt{ }$ \\
\hline $180^{\circ}$ & - & - & - & - & - & - \\
\hline \multicolumn{7}{|c|}{ Presentase Error : $20 \%$} \\
\hline
\end{tabular}

Tabel 2. Pengujian Jarak Sensor di rumah nyata

\begin{tabular}{|c|c|c|c|c|c|c|}
\hline \multirow{2}{*}{ Sudut } & \multicolumn{7}{|c|}{ Jarak } \\
\cline { 2 - 7 } & $1 \mathrm{~m}$ & $2 \mathrm{~m}$ & $5 \mathrm{~m}$ & $7 \mathrm{~m}$ & $8 \mathrm{~m}$ & $10 \mathrm{~m}$ \\
\hline $0^{\circ}$ & $\sqrt{ }$ & $\sqrt{ }$ & $\sqrt{ }$ & $\sqrt{ }$ & - & - \\
\hline $65^{\circ}$ & $\sqrt{ }$ & $\sqrt{ }$ & $\sqrt{ }$ & $\sqrt{ }$ & - & - \\
\hline $90^{\circ}$ & $\sqrt{ }$ & $\sqrt{ }$ & $\sqrt{ }$ & $\sqrt{ }$ & - & - \\
\hline $120^{\circ}$ & $\sqrt{ }$ & $\sqrt{ }$ & $\sqrt{ }$ & $\sqrt{ }$ & - & - \\
\hline $180^{\circ}$ & - & - & - & - & - & - \\
\hline \multicolumn{7}{|c|}{ Presentase Error $: 54 \%$} \\
\hline
\end{tabular}

Dari hasil pengujian ini, pada tabel 1 sensor PIR bisa mendeteksi objek sampai 100 centimeter dengan sudut 0,65, 90, 120 derajat terhadap target, tetapi tidak bisa detect sudut sensor 180 derajat. Sedangkan untuk tabel 2 sensor PIR bisa mendeteksi adanya pergerakan sampai jarak 7 meter atau 21 feet dan sudut sensor $0,65,90,120$ derajat, tetapi tidak bisa detected dari jarak 8 meter atau 30 feet keatas dan sudut sensor 180 derajat.

5. Hasil Pengujian Durasi

Dalam pengujian ini untuk mendeteksi apakah benar atau tidak sensor PIR akan aktif jika pergerakan. Nantinya direkam kamera lalu disimpan di raspberry selanjutnya dikirim ke telegram. Data tersebut berupa video mp4 dengan resolusi rendah sampai resolusi tinggi. Pengujian dilakukan prototype rumah disajikan pada tabel 3 yang nantinya akan diuji ada pergerakan pada prototype dan rumah nyata

Tabel 3. Pengujian Durasi Video di Prototype dan Rumah Nyata

\begin{tabular}{|c|c|c|c|}
\hline $\begin{array}{c}\text { Pengujian } \\
\text { objek }\end{array}$ & $\begin{array}{c}\text { Resolusi } \\
\text { (pixel) }\end{array}$ & $\begin{array}{c}\text { Durasi } \\
\text { prngiriman } \\
\text { notifikasi } \\
\text { (detik) }\end{array}$ & $\begin{array}{c}\text { Durasi } \\
\text { video } \\
\text { (detik) }\end{array}$ \\
\hline $\begin{array}{c}\text { Pergerakan } \\
\text { mobil-mobilan }\end{array}$ & $160 \times 120$ & 2.10 & 18 \\
\hline $\begin{array}{c}\text { Pergerakan } \\
\text { mobil-mobilan }\end{array}$ & $640 \times 480$ & 4.00 & 16 \\
\hline $\begin{array}{c}\text { Pergerakan } \\
\text { mobil-mobilan }\end{array}$ & $1280 \times 960$ & 8.00 & 3 \\
\hline $\begin{array}{c}\text { Pergerakan } \\
\text { manusia }\end{array}$ & $160 \times 120$ & 2.20 & 18 \\
\hline $\begin{array}{c}\text { Pergerakan } \\
\text { motor }\end{array}$ & $640 \times 480$ & 4.20 & 3 \\
\hline $\begin{array}{c}\text { Pergerakan } \\
\text { mobil }\end{array}$ & $1280 \times 960$ & 10.0 & 16 \\
\hline Presentase Error : $0 \%$ & & \\
\hline
\end{tabular}

6. Analisis Data

Dalam pembuatan hardware, peneliti merancang desain serta fungsi dari masing masing komponen sehingga ketika dijalankan dapat menghasilkan output sesuai dengan yang diinginkan. Dalam tahap pengujian hardware ini dilakukan dengan tujuan untuk mengetahui error yang ditimbulkan dari masing - masing komponen tersebut. Berikut cara menghitung error dan persentase error :

Error $=|\mathrm{Xi}-\mathrm{Xp}|$

$\%$ Error $=|X i-X p / X p| \times 100 \%$

Keterangan :

$\mathrm{Xi}=$ Nilai pengukuran pada kontroler

$\mathrm{Xp}=$ Nilai pengukuran sesungguhnya pada alat ukur.

\section{PENUTUP}

Dari pengujian dan analisa dapat disimpulkan bahwa alat dapat berkerja dengan baik. Pengguna dapat mengaktifkan kamera jika berpergian keluar rumah dan bisa mengontrol aktifitas mencurigakan depan rumah. Kamera dapat merekam aktifitas jika ada gerakan di depan rumah jika sensor PIR mendeteksi pergerakan tersebut dan akan mengirim pergerakan dalam bentuk video mp4. Dan alat juga dapat dikontrol dari jarak jauh melalui aplikasi Telegram.

\section{REFERENSI}

[1] Tri Fajar Yurmama S, "Perancangan Software Aplikasi Pervasive Smart Home,” 2009.

[2] Rezki Mishar, "Pengenalan dan Pengembangan Smart City ," LPIK, 2015. .

[3] S. L. Keoh, S. S. Kumar, and H. Tschofenig, "Securing the internet of things: A standardization perspective," IEEE Internet Things J., vol. 1, no. 3, pp. 265-275, 2014, doi: 10.1109/JIOT.2014.2323395.

Apri Junaidi, "Internet Of Things, Sejarah, Teknologi Dan Penerapannya : Review," 2015.

[5] K. D. Setyanto and I. Fibriani, "Pengendalian Mobile Robot Vision," Arus Elektro Indones., 2016.

[6] A. S. Umam, B. Supeno, and W. Cahyadi, "Sistem Keamanan Ruangan Berbasis WEB Menggunakan Webcam dan Sensor PIR," J. Arus Elektro Indones., vol. 2, no. 2, pp. 1-6, 2016, [Online]. Available: https://jurnal.unej.ac.id/index.php/EJAEI/article/view/3026. Smartphone, Pemanfaatan Dan Tingkat Usability Pada 
Android Dan iOS Platforms," InfoTekJar (Jurnal Nas. Inform. dan Teknol. Jaringan), vol. 3, no. 2, pp. 184192, 2019, doi: 10.30743/infotekjar.v3i2.1002.

[8] M. Elektrika and A. Sarwono, "Rancang Bangun Sistem Monitoring Dengan Video Streaming Dan Recording Sebagai Pemantau Ruangan Kelas Menggunakan," vol. 12, no. 2, pp. 79-92, 2019.

[9] Hendri Masdi, "Development of D-statcom for Voltage Sag Mitigation," Univ. putra malaysia, 2011.

\section{BiodataPenulis}

Monita, lahir di Palembang, 22 Mei 1998. Sedang menempuh jenjang sarjana pada Program Studi Teknik Elektro Industri di jurusan Teknik Elektro FT UNP.

Drs. Hendri, M.T, Ph.D, lahir di Padang, 17 September 1964. Beliau memperoleh gelar Sarjana Teknik di Universitas Negeri Padang pada tahun 1989. Kemudian melanjutkan jenjang pendidikan S2 di ITB dan memperoleh gelar Master dari Institut Teknologi Bandung (ITB) pada tahun 2000. Selanjutnya beliau kembali melanjutkan S3 untuk mendapatkan gelar Ph.D di Jurusan Teknik Elektro dan Elektronik, Fakultas Teknik University Putra Malaysia tahun 2010. Beliau juga aktif menjadi staf pengajar di Fakultas Teknik khususnya di Teknik Elektro FT UNP sampai sekarang. 